\title{
Determinants of compliance with methylphenidate therapy in children
}

\author{
JACQUELINE G. HUGTENBURG ${ }^{1,2}$, IVO WITTE ${ }^{1} \&$ EIBERT R. HEERDINK $^{1}$ \\ ${ }^{1}$ Department of Pharmacoepidemiology and Pharmacotherapy, Faculty of Pharmaceutical Sciences, Utrecht University, \\ Utrecht, the Netherlands, and ${ }^{2}$ Department of Medical Pharmacology, VU University Medical Centre, Amsterdam, the \\ Netherlands
}

\begin{abstract}
Aim: To get more insight into factors that influence compliance with the use of methylphenidate. Methods: 22 pharmacies detected children who used methylphenidate. Their parents were sent a questionnaire on the use of methylphenidate. In a case-control study, the influence of patient- and drug-related factors on compliance, as reported by parents, was determined. Results: Parents returned 117 (75\%) of 157 questionnaires sent out. Of these, $47.8 \%$ of the children missed a dose two times a month or more. Forgetting to take the medication (87.9\%) was the most important reason. The casecontrol study showed that children of 16-18 y were more likely to miss doses. Other patient- and drug-related factors did not influence the missing of doses.
\end{abstract}

Conclusion: A number of known determinants for compliance do not influence the missing of doses of methylphenidate. With about $80 \%$ of the parents reporting that their child missed doses of methylphenidate less than 5 times per month, compliance was quite good for the majority of the children.

Key Words: Case-control study, children, compliance, determinants, efficacy, methylphenidate, side effects

\section{Introduction}

Methylphenidate is the most frequently used psychoactive drug in the treatment of attention-deficit/ hyperactivity disorder (ADHD) [1]. The efficacy of methylphenidate has been shown in a number of placebo-controlled trials and meta-analyses $[1,2]$. Non-compliance, however, may limit the effectiveness of a drug in daily practice $[3,4]$. Several drug-related factors such as lack of effect and side effects are known to influence compliance [5]. Compliance also decreases with the frequency that drugs have to be taken $[6,7]$.

Only limited data on compliance with the use of methylphenidate by children are available. A recent review by Swanson [8] addresses studies of compliance with stimulants. It was found that rates of noncompliance varied from 20 to $65 \%$ depending on the methods used for the assessment of compliance and the definitions used. In a preliminary study using drug dispensing data of pharmacies, we have shown that about half of the children were compliant with drug therapy [9]. In this study, we used refill data from pharmacies, which may not have been an accurate measure of compliance. Data on the determinants for non-compliance, however, are only scarcely available. The aim of the present study was to gain more insight into the influence of patient- and drug-related factors on children's compliance with the use of methylphenidate.

\section{Methods}

\section{Setting and study population}

Between September 2002 and February 2003 a study on the compliance with drug use was performed among children using methylphenidate. Twenty-two community pharmacies included children who used methylphenidate. Inclusion criteria were an age younger than $18 \mathrm{y}$, and the use of methylphenidate for at least three consecutive months and at the time of the study. When the pharmacy detected more than 10 children, pharmacists used a random table to select 10 children. The pharmacists asked the children's parents or their guardians by phone whether they were willing to fill in a questionnaire about their children's drug use. When parents refused to participate, another child was selected until all or a maximum of 10 children participated. 


\section{Questionnaire}

A questionnaire was sent to the parents of the children included. The questionnaire included questions on the use of methylphenidate (dose and timing of drug intake), on experience with the drug (effectiveness and side effects) and on compliance with use (use at the weekends, holidays shorter than 2 , and summer holidays, as well as on the missing of doses and the underlying reasons).

\section{Data analysis}

A case-control analysis was performed with cases defined as children whose parents reported that three or more doses per month were passed over and controls defined as all other children. Possible determinants were analysed using unconditional logistic regression, adjusted for possible confounding.

\section{Results}

\section{Response and basic characteristics}

Of 157 questionnaires sent, 117 (75\%) were returned. One hundred and four $(88.9 \%)$ questionnaires were from boys and $13(11.1 \%)$ were girls. In the age categories $4-10 \mathrm{y}, 11-15 \mathrm{y}$ and $16-18 \mathrm{y}$ there were $34(29 \%), 60(51.3 \%)$ and $23(19.7 \%)$ children, respectively.

\section{Drug dose and drug use}

Of the study population, $15.4 \%, 49.6 \%, 19.7 \%, 8.5 \%$ and $6.8 \%$ of the children used $10-20 \mathrm{mg}, 20-30 \mathrm{mg}$, $30-40 \mathrm{mg}, 40-50 \mathrm{mg}$ and $50 \mathrm{mg}$ or more per day, respectively; and $1.7 \%, 53.0 \%$ and $35.3 \%$ of the children used methylphenidate on a once-daily, twicedaily and trice-daily regimen, respectively. Forty-two per cent of the children used a lower dose when taking the second or third dose. At weekends, holidays shorter than $2 \mathrm{wk}$ and summer holidays, $38.5 \%$, $25.7 \%$ and $30.8 \%$ of the children used a reduced dose of methylphenidate or no drug at all.

Parents were also asked whether their child missed doses independent of a possible intentionally reduced intake during weekends and holidays. Fifty-seven children $(48.7 \%)$ missed a dose two times a month or less, $28(24 \%)$ children three or four times a month, while $22(18.4 \%)$ missed a dose five times a month or more. The most important reasons for the missing of doses included: forgetting $(84.9 \%)$, sufficient effect $(8.6 \%)$ and side effects $(5.4 \%)$.

The results of the case-control analysis of the relationship between patient- and drug-related factors and the missing of three doses a month or more (cases) are shown in Table I. The adjusted odds ratio (OR) for children aged 16-18 y and the crude OR for lack of motivation are significantly higher than 1 . For the other factors, no influence was found.

\section{Discussion}

The results of the present study show that the missing of doses of methylphenidate was not influenced by various patient- and drug-related factors. This is consistent with parents' reports that forgetting a dose was the main reason for the missing of doses. This is in contrast to the literature, because several drug-related factors including dose frequency, drugs effectiveness and side effects

Table I. Results of a case-control study on the influence of a number of patient- and drug-related variables and the passing over of three times a month or more of methylphenidate doses (cases).

\begin{tabular}{|c|c|c|c|c|}
\hline Variable & Case (60) $n(\%)$ & Controls (57) $n(\%)$ & OR $(95 \% \mathrm{CI})$ & adjusted OR (95\% CI) \\
\hline Boy & $52(86.7)$ & $52(91.2)$ & $0.63(0.15-2.34)$ & $0.85(0.21-3.41)$ \\
\hline \multicolumn{5}{|l|}{ Age (y) } \\
\hline $0-10$ & $17(28.3)$ & $27(47.4)$ & reference & reference \\
\hline $11-15$ & $31(51.7)$ & $27(47.4)$ & $1.82(0.76-4.38)$ & $1.53(0.52-4.44)$ \\
\hline $16-18$ & $12(20.0)$ & $3(5.2)$ & $6.35(1.39-38.92)$ & $8.52(1.08-67.36)$ \\
\hline \multicolumn{5}{|l|}{ Daily dose (mg) } \\
\hline $10-20$ & $10(16.7)$ & $8(14.0)$ & reference & reference \\
\hline $20-30$ & $30(50.0)$ & $28(49.1)$ & $0.86(0.26-2.80)$ & $0.59(0.15-2.33)$ \\
\hline $30-40$ & $8(13.3)$ & $15(26.3)$ & $0.43(0.10-1.80)$ & $0.19(0.04-0.99)$ \\
\hline $40-50$ & $7(11.7)$ & $3(5.3)$ & $1.87(0.29-14.58)$ & $0.55(0.06-4.97)$ \\
\hline More than 50 & $5(83.3)$ & $3(5.3)$ & $1.33(0.18-11.19)$ & $0.27(0.03-3.03)$ \\
\hline \multicolumn{5}{|l|}{ Dose frequency } \\
\hline 1 or 2 times daily & $26(43.3)$ & $24(42.1)$ & reference & reference \\
\hline twice daily, tapering & $7(11.7)$ & $7(12.3)$ & $0.92(0.24-3.51)$ & $0.83(0.18-3.81)$ \\
\hline 3 times daily & $8(13.3)$ & $10(17.5)$ & $0.74(0.22-2.47)$ & $0.88(0.21-3.76)$ \\
\hline 3 times daily, tapering & $19(31.7)$ & $16(28.1)$ & $1.10(0.42-2.85)$ & $1.38(0.48-3.96)$ \\
\hline Lack of motivation & $21(35.0)$ & $9(15.8)$ & $2.86(1.09-6.25)$ & $2.78(0.48-16.67)$ \\
\hline Child experiences effect & $56(93.3)$ & $55(96.5)$ & $0.51(0.04-3.74)$ & $2.54(0.14-45.43)$ \\
\hline \multicolumn{5}{|l|}{ Side effects } \\
\hline 0 & $10(16.7)$ & $8(14.0)$ & reference & reference \\
\hline $1-2$ & $23(38.3)$ & $25(43.9)$ & $0.74(0.22-2.49)$ & $0.76(0.21-2.73)$ \\
\hline $3-4$ & $21(35.0)$ & $19(33.3)$ & $0.88(0.25-3.11)$ & $1.06(0.29-3.84)$ \\
\hline 5 or more & $6(10.0)$ & $5(8.8)$ & $0.96(0.16-5.61)$ & $0.99(0.17-5.73)$ \\
\hline
\end{tabular}


are known determinants of compliance with drug use [3]. Obviously, determinants for compliance with certain drug therapies are not necessarily determinants for compliance with the use of other drugs. Firestone et al. [10] and Brown et al. [11] found an association with socio-economic and demographic factors. Children who were younger, male and had a lower IQ, and parents with a lower IQ were less compliant. The former study [10] only addressed discontinuation of the drug, whereas the latter study [11] was a small study with only 34 children completing treatment with placebo or methylphenidate.

Children aged 16 to $18 \mathrm{y}$ were more likely to miss doses of methylphenidate. It is possible that, at this age, children to a greater extent manage their drug use themselves and that therefore parents are less certain about the intake of their children's drugs.

The present study shows that, according to parents' reports, about $50 \%$ of the children miss a dose three times a month or more, and about $20 \%$ miss a dose five times a month or more. According to parents' reports, we can conclude that the compliance of the majority of the children is quite good. This is in agreement with the expected result, since the effect of missing a dose usually shows itself as an immediate increase of the symptoms of hyperactive behaviour or an increase of inattentiveness. Similar to the results of our previous study in which compliance was calculated by using pharmacy prescription data [9], it appeared that compliance was good in the case of more than $50 \%$ of the children.

\section{Efficacy}

In randomised controlled studies and meta-analyses, methylphenidate was considered effective in about $70 \%$ of children $[1,2]$. In our study, $95 \%$ of the parents were satisfied with the effectiveness of the drug. It is very likely that children who did not experience sufficient efficacy of the drug had already stopped using methylphenidate.

It was remarkable that about $85 \%$ of parents reported side effects, whereas other studies have shown that only 20 to $30 \%$ of children experience side effects [12-14]. However, other studies have also shown that parents of children who use methylphenidate report more side effects than one might expect on the basis of data obtained from clinical trials [15].

\section{Limitations}

The present study included current users of methylphenidate. Therefore, children who had stopped using the drug were not included. As a result, non-compliance resulting in discontinuation of the drug has not been studied. At $75 \%$, the response rate is very high. Therefore, the influence of non-responders is low. A limitation may be the result of recall bias. Parents may not know the precise answers anymore or do not exactly know whether or not their child uses the drug at school.

Twenty-two pharmacies from different parts of the Netherlands participated in the study. With 117 patients included, the results are representative for the Netherlands.

\section{Conclusion}

A number of known determinants for compliance do not influence the missing of doses of methylphenidate. With about $80 \%$ of parents reporting that their child misses doses of methylphenidate less than five times per month, compliance is quite good for the majority of the children.

\section{References}

[1] Greenhill LL, Halperin JM, Abikoff H. Stimulant medications. J Am Acad Child Adolesc Psychiatry 1999;38:503-12.

[2] The MTA Cooperative Group. A 14-month randomized clinical trial of treatment strategies for attention-deficit/hyperactivity disorder. Arch Gen Psychiatry 1999;56:1073-86.

[3] DiMatteo MR. Variations in patients' adherence to medical recommendations: a quantitative review of 50 years of research. Med Care 2004;42:200-9.

[4] Epstein LH. The direct effects of compliance on health outcome. Health Psychology 1984;3:385-93.

[5] Weintraub M, Au W, Lasagna L. Compliance as a determinant of serum digoxin concentration. JAMA 1973;224:481-5.

[6] Paes AHP, Bakker A, Soe-Agnie CJ. Impact of dosage frequency on patient's compliance. Diabetes Care 1997;20: 1512-6.

[7] Pullar T, Birtwell AD, Wiles PG, Hay A, Freely MP. Use of a pharmacological indicator to investigate compliance with tablets to be taken once, twice or three times daily. Clin Pharmacol Ther 1988;44:540-5.

[8] Swanson J. Compliance with stimulants for attention-deficit/ hyperactivity disorder. CNS Drugs 2003;17:117-31.

[9] Hugtenburg JG, Griekspoor JE, Heerdink ER, Tso YH, Egberts ACG. Children's compliance with methylphenidate: drug use calculated with pharmacy records and use, effects and side effects as reported by parents. Pharm World Sci 2005; 27:197-201.

[10] Firestone P. Factors associated with children's adherence to stimulant medication. Am J Orthopsychiatr 1982;21:474-9.

[11] Brown RT, Borden KA, Wynne ME, Spunt AL, Clingerman SR. Compliance with pharmacological and cognitive treatments for attention deficit disorder. J Am Acad Child Adolesc Psychiatr 1987;26:521-6.

[12] Gezondheidsraad: Diagnostiek en behandeling van ADHD. Publicatie nr 2000/24. Den Haag: Gezondheidsraad; 2000.

[13] Barkley RA, McMurray MB, Edelbrock CS, Robbins K. Side effects of methylphenidate in children with attention deficit hyperactivity disorder: a systemic, placebo-controlled evaluation. Pediatrics 1990;86:184-92.

[14] Efron D, Jarman F, Barker M. Side effect of methylphenidate and dexamphetamine in children with attention deficit hyperactivity disorder: a double-blind, crossover trial. Pediatrics 1997;100:662-6.

[15] Schachter HM, Pham B, King J, Langford S, Moher D. How efficacious and safe is short-acting methylphenidate for the treatment of attention-deficit disorder in children and adolescents? A meta-analysis. CMAJ 2001;165:1475-88. 